\title{
Continuing Education of the Elderly in China: Regional Difference and Family Welfare Promotion

\author{
Hao Wang ${ }^{1, a}$ \\ a15863757390@163.com
} \\ ${ }^{1}$ School of Economics, Shanghai University, Shanghai 200444, China
}

\begin{abstract}
Keywords: Continuing education; Education of the elderly; Lifelong education; Regional difference; Family welfare
\end{abstract}

\begin{abstract}
Education of the elderly has become an important component of Chinese continuing education and lifelong education system. Although elderly education has received much academic attention, there is a lack of empirical research on the view of the Chinese elderly's educational development and effect. Based on questionnaire results of CHARLS database, the regional difference, among the eastern, the western, the northeastern and the midland, and family welfare promotion of the Chinese elderly's continuing education are demonstrated. It is illustrated that the regional development differences in the education for the elderly of China, the eastern which is ahead of other regions in economy was not better than the western in the development of education of the elderly. Meanwhile there is a mismatch between aging degree and development of education of the elderly. Chinese family welfare promoted by continuing education of the elderly is analyzed through Probit Regression Model. As a conclusion, developing the facilities for education of the elderly improves the family welfare of the surrounding residents.
\end{abstract}

\section{Introduction}

Continuing education of the elderly, as an important component of Chinese continuing education and lifelong education system [1], has received much attention from government and academics with the increasingly serious of aging in China. It is generally accepted that developing continuing education of the elderly is essential for the construction of a learning society in China.

China has been into aging society since 2000 , and about $10.8 \%$ of Chinese populations are more than 65 years old in 2016, this scale has far exceeded 7\%, which was the boundary of aging society made by the United Nations. That means that China has entered a stage of severe aging. Aging has brought a series of economic and social problems, such as the problem of "getting old before getting rich", which not only brings serious pension pressure to Chinese families and government, but also makes a challenge of the elderly's life quality. According many studies, continuing education of the elderly can solve these problems, and promote the construction of active aging.

Previous studies show that education of the elderly can solve the social and economy problems brought by aging. First of all, education of the elderly can meet the elderly's increasing spiritual and cultural needs, which can improve the life quality of the elderly $[2,3]$. Secondly, the education of the elderly can further explore the accumulation of elderly population's human capital, which can become a new driving for the development of economy [4]. In addition, improving the quality of overall aging population through education of the elderly is beneficial to the sustainable development of society, and it is important to the construction of lifelong education system $[5,6]$.

In this essay, continuing education of the elderly includes two forms, one is professional education for the elderly, which usually held by the university for the senior citizens, nursing home and distance education [7,8], the other is the community education for the elderly, which represented by elderly association and activity center for the elderly $[9,10]$. This paper aims at the regional development difference in education of the elderly and proves the effect of aging education in family welfare promotion, which is based on CHARLS database's questionnaire results.

The sample data of this article comes from the questionnaire results of CHARLS, which full name is China health and retirement longitudinal study (CHARLS). The primary data about the 
education facilities is obtained from the community questionnaire results of 2011 CHARLS wave 1 survey and the data about the basic information of the elderly surveyed is gained from the 2013 CHARLS wave 2 survey. Because CHARLS 2011 and CHARLS 2013 are successive tracking investigations, the data gained from those two waves' surveys can be matched perfectly.

\section{Regional Development Difference in Education of the Elderly}

In this section, it is illustrated that the general development situation and the regional development differences in the education of the elderly in China, to compare among provinces or among the eastern, the western, the northeastern and the midland of China. The region division method follows the relevant instructions from National Bureau of Statistics of the People's Republic of China, which will be explained below.

In general, the professional education for the elderly has developed better than community education in China. Since 1980s, China has begun the attempt of the university for the senior citizens, and more than 7 million elderly citizens have been studied in those institutions by the year 2016. In contrast, the community education for the elderly is a new subject in China, while many studies show the improving the development of community education is the key to the construction of Chinese education system of the elderly [11]. The next part, based on the questionnaire results of CHARLS database, it is illustrated that the regional development differences in the education of the elderly in China

In the community questionnaire of CHARLS (2011\&2013), there are some questions about the institutions for education of the elderly. In this part, a formulation is constructed to measure the development of the aging education, which means the level of regional development is equal to the mean number of facilities over the communities surveyed, the formulation can be written as:

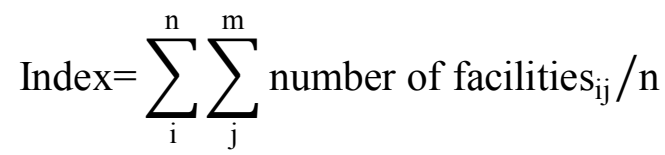

i: the different communities surveyed

$\mathrm{j}$ : the different kinds of facilities for education of the elderly, including: university for the senior citizens, activity center for the elderly, elderly association and nursing home.

The results are expressed by a layered map (Fig. 1) and a result list in table 1 as follow:

Table 1 The index of aging education development

\begin{tabular}{|c|c|c|c|c|c|}
\hline & China & Eastern & Midland & Western & Northeastern \\
\hline Index & 5.16 & 5.14 & 5.12 & 5.16 & 4.73 \\
\hline
\end{tabular}




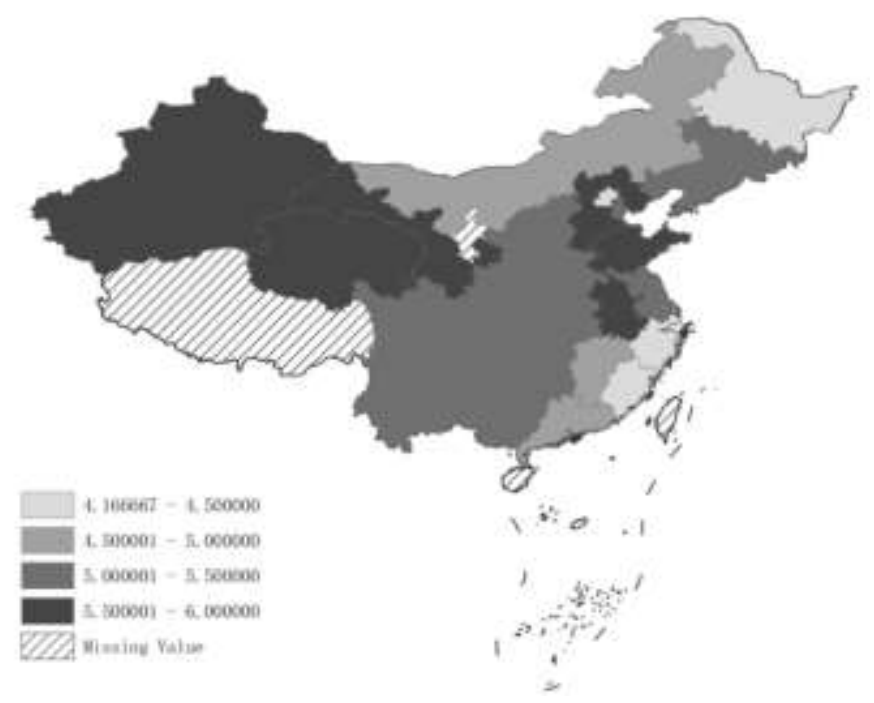

Figure 1. The regional development difference in education of elderly

According to Fig. 1 and Table 1, there is an obvious regional difference in the development of education of the elderly. The eastern where is ahead of other regions in economy was not better than the western in the development of education for the elderly, especial the development of aging population in Guangdong and Fujian is lower than the provinces in the Midland and the Western. The index of the Northeastern is lower than the other regions.

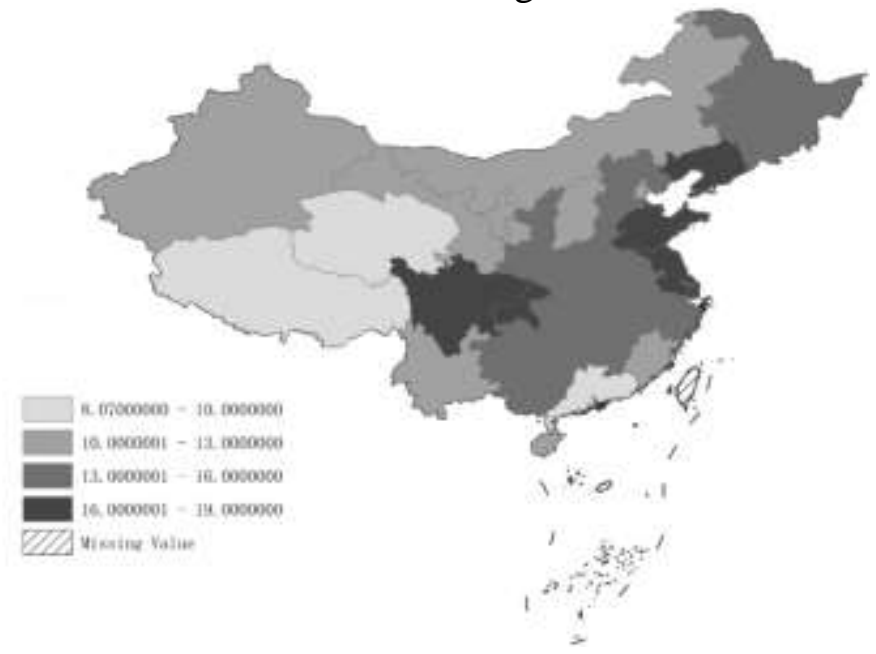

Figure 2. The regional difference in aging degree

To compare with the aging degree's situation in Fig. 2, this is the graph of old-age dependency ratio in 2015. There is a mismatch between aging degree and development of education of the elderly. The aging education in western has developed well, but this region is not in the deepest aging stage. The aging of the population in northeastern is relatively serious than the western, but the development of aging education is relatively backward.

\section{Family Welfare Promotion from Education of the Elderly}

In this section, Chinese family welfare promoted by continuing education of the elderly is analyzed through Probit Regression Model. A developed system of aging education can improve the life quality of the elderly who participate and promote the welfare of their family.

The empirical model can be written as:

$$
\operatorname{Prob}(\text { Happy }=1)=\varnothing\left(\alpha_{1}+\beta_{1} \text { Index }+\beta_{2} X\right)
$$

Happy: Happiness of the elderly, based on the questionnaire results of CHARL 2013. If the 
answer of the elderly surveyed is satisfied, Happy $=1$, otherwise Happy $=0$. The happiness is the agent variable of the welfare.

Index: Development of education for the elderly, based on the previous results

$\mathrm{X}$ : Control variable about basic situation of the elderly surveyed, based on the questionnaire results of CHARL 2013, such as the gender, the marital status, the education level, the pension and many variable can have influence on the happiness of the elderly.

Table 2 The results of Probit Regression Model

\begin{tabular}{c|c}
\hline Independent variable & Coefficient \\
\hline Index & 0.007 \\
\hline Control variable & Yes \\
\hline Fixed effect & Yes \\
\hline
\end{tabular}

According the result of Probit regression, developing the facilities for education of the elderly improves the family welfare of the surrounding residents, but the effect is not very significant. This means the development of Chinese aging education have effect on the elderly's welfare, but it needs further improvement than before. This result show that the participation of aging education is not very high, which means many senior citizens do not learn or entertain in those facilities for the elderly. Because Chinese aging education is led by government, the government should improve the support from relevant policies, such as subsidy to the elderly or empowerment to those facilities.

\section{Summary}

In these years, continuing education of the elderly in China received much attention from government and academics. It has become an important part of Chinese continuing and lifelong education systems. The professional education for the elderly represented by university for senior citizens has developed better than community education, while the community education is the key to development in the future.

There are significant regional differences in the development of education for the Chinese elderly. It is not proportional to the development of economy. Meanwhile there is a mismatch between aging degree and development of education of the elderly, the region in serious aging degree like the northeastern of China has not developed well in education of the elderly. In addition, although continuing education of the elderly has effect on welfare promotion of the elderly and their families, the effect is not very significant. That means that government should improve the relevant policies to increase the senior citizens' participation in education.

\section{References}

[1] J. Xu, Y. Lee. An Empirical Study of How Far the Learning Needs of Chinese Older Adults Being Matched. Modern Distance Education Research, Vol. 144(2016), No.6, p.39-46 (in Chinese)

[2]X.S. Li. Reflection on the Development and Research into Elderly Education Home and Abroad. Comparative Education Review, Vol. 298(2014), No.11, p.54-59 (in Chinese)

[3] M.B. Lakin. Forging New Identities: Older Adults in Higher Education. International Journal of Continuing Education \& Lifelong Learning, 2009, Vol. 2, p.33-44

[4] X. Yuan, Y. Gao and J.B. Li. The Concept of Demographic Dividend and Reconsideration of Demographic Dividend in China: Focusing on the Demographic Opportunity. Chinese Journal of Population Science, 2017, No.6, p.19-31(in Chinese)

[5] M. Shinagel. Demographics and Lifelong Learning Institutes in the 21 st Century. Continuing Higher Education Review, Vol. 76(2012), p.20-29

[6] F. DiSilvestro. Continuing Higher Education and Older Adults: A Growing Challenge and Golden Opportunity. New Directions for Adult \& Continuing Education, Vol. 140(2013), 
p.79-87

[7] R. Swindell. U3A Online: A Virtual University of the third age for isolated older people. International Journal of Lifelong Education, Vol. 21(2002), p.414-429

[8] J.W. Weaver. Special Issue: Aging Education: Preparing for the 21st Century Introduction. Educational Gerontology, Vol.25(1999), p.475-477

[9] X. Dong, et al. Evaluation of Community Health Education Workshops among Chinese Older Adults in Chicago: A Community-Based Participatory Research Approach. Journal of Education \& Training Studies, Vol.1(2013), p.170-181

[10]L. Gao, X. Cao and M. Zhang. The Study on Community Health Education of Empty Nest Elderly. Engineering, Vol.10(2013), p.137-139

[11]J. Wang, L. X. A Summary of Studies on the Education of the Elderly in Community in Recent Ten Years. Journal of Continuing Higher Education, Vol.30(2017), P.72-76(In Chinese) 